\section{Category}

Polymer-Supported

Synthesis

\section{Key words}

1,4-addition

transfer

hydrogenation

micelle reactor

photoswitching

rhodium catalysis

tandem catalysis

X. P. QU, M. KUEPFERT, M. HASHMI, M. WECK* (NEW YORK UNIVERSITY, USA) Compartmentalization and Photoregulating Pathways for Incompatible Tandem Catalysis J. Am. Chem. Soc. 2021, 143, 4705-4713, DOI: 10.1021/jacs.1c00257.

\title{
Tandem Asymmetric Michael/Transfer Hydrogenation by Using a Dual Rh-Incorporated Micelle Reactor
}
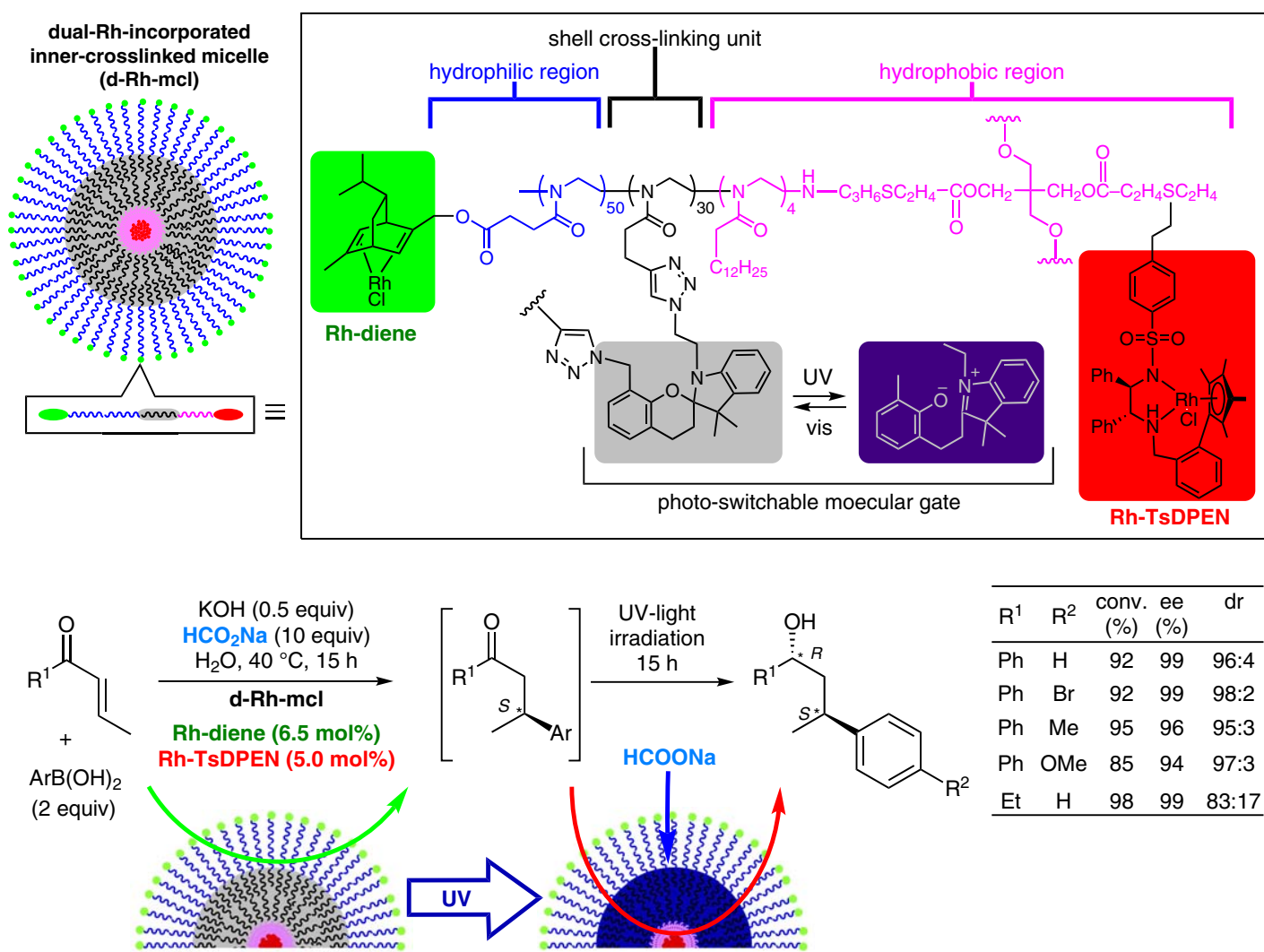

\begin{tabular}{ccccc}
\hline $\mathrm{R}^{1}$ & $\mathrm{R}^{2}$ & $\begin{array}{c}\text { conv. } \\
(\%)\end{array}$ & $(\%)$ & $\mathrm{dr}$ \\
\hline $\mathrm{Ph}$ & $\mathrm{H}$ & 92 & 99 & $96: 4$ \\
$\mathrm{Ph}$ & $\mathrm{Br}$ & 92 & 99 & $98: 2$ \\
$\mathrm{Ph}$ & $\mathrm{Me}$ & 95 & 96 & $95: 3$ \\
$\mathrm{Ph}$ & $\mathrm{OMe}$ & 85 & 94 & $97: 3$ \\
$\mathrm{Et}$ & $\mathrm{H}$ & 98 & 99 & $83: 17$ \\
\hline
\end{tabular}

Significance: Homochiral Rh-diene and Rh-TsDPEN units were incorporated stepwise into the hydrophilic outer shell and the hydrophobic core regions, respectively, of micelles of a polyoxazolinebased amphiphilic triblock copolymer bearing spiropyran crosslinks (d-Rh-mcl). The $\mathbf{d}$-Rh-mcl micelles catalyzed an asymmetric 1,4-addition of arylboronic acids to $\alpha, \beta$-unsaturated ketones in water (15 h) to give (S)-3-arylketone intermediates; successive asymmetric transfer hydrogenation of these (S)-intermediates under UV irradiation (15 h) gave the corresponding $(1 R, 3 S)$-3-arylbutanols in high yields and with excellent enantioselectivity.
Comment: The spiropyran cross-linker is a photoresponsive unit that isomerizes to a hydrophilic zwitterionic merocyanine under UV irradiation. Thus, the initial 1,4-addition took place in the hydrophilic corona region of the anchored Rh-diene complex in the absence of UV irradiation. Upon UV irradiation, the zwitterionic merocyanine increased the permeability of the Rh-TsDPEN core region toward water-soluble HCOONa, to promote the transfer hydrogenation in the second reaction step. The 1,4-addition and transfer hydrogenation compete under homogeneous conditions. The photoinduced gating between the compartmentalized catalytic regions was essential for regulating the incompatible multiple catalytic steps. 